\title{
Educação Física e Envelhecimento: uma reflexão sobre a necessidade de novos olhares e práticas
}

\author{
Alessandra Galve Gerez ${ }^{1,2}$ \\ Marília Velardi ${ }^{3,4}$ \\ Fabiano Marques Câmara ${ }^{2,5}$ \\ Maria Luiza de Jesus Miranda ${ }^{3,4}$
${ }^{1}$ Universidade do Grande $A B C$ - UniABC, Santo André, SP, Brasil
${ }^{2}$ Integrante do Grupo de Estudo e Pesquisa Sênior - GREPES e do Laboratório de
Estudo e Pesquisa Biopsicossoais do Movimento Humano - LEPEBIMH
${ }^{3}$ Coordenadora do Projeto Sênior para a Vida Ativa da Universidade São Judas Tadeu, São Paulo, SP, Brasil
${ }^{4}$ Coordenadora do Grupo de Estudo e Pesquisa Sênior- GREPES
${ }^{5}$ Faculdades Integradas Metropolitanas de Campinas - METROCAMP, Campinas, SP, Brasil

\begin{abstract}
Resumo: Em função do aumento da população idosa tem havido um crescimento significativo dos programas de Educação Física/Atividade Física para esta população, surgindo a necessidade de reflexões criticas acerca dos papéis atribuídos à Educação Física no envelhecimento e dos paradigmas que embasam seus discursos e práticas atuais que, norteados pelos interesses do Capital, tendem a reforçar preconceitos e estereótipos. Assim, o objetivo deste ensaio foi refletir criticamente sobre os papéis da Educação Física no contexto do envelhecimento. Para tanto, foi resgatado o paradigma científico hegemônico que fundamenta e determina as práticas na área da Saúde e, consequentemente, na Educação Física, para, por fim, apontarmos a necessidade de sua superação.
\end{abstract}

Palavras-chave: Educação Física. Idosos. Saúde.

\section{Physical Education and Aging: a reflexion on the need of a new approach and practice}

\begin{abstract}
Due to the increase of the aging population, there have been a significant number of Physical Education/Physical Activity programs designed for them. It comes to time when the role of Physical Education in the aging process needs to be critically analyzed as well as the paradigm that the discourse and practice are based on, which, by been guided by economic interests, emphasize prejudice and stereotypes. The aim of this study is to reflect upon the role of Physical Education in the aging context. The hegemonious scientific paradigm, that is the foundation and determinant of the Health practice and thus the Physical Education practice will be analyzed so that the need to go beyond this hegemony can be pointed out.
\end{abstract}

Key Words: Physical Education. Elderly. Health.

\section{Introdução}

Como já é de conhecimento geral nos últimos anos houve um aumento significativo da população idosa mundial (FREITAS, 2004). Paralelamente a este fenômeno, crescem, também, programas voltados para $o$ atendimento das necessidades médicas, sociais e educacionais dos idosos. No Brasil, a maior frequência de propostas oferecidas a essa população está voltada para programas de prevenção e promoção da saúde $e$ as Universidades da Terceira Idade (ASSIS et al., 2004; CACHIONI; NERI, 2004; DEBERT e NERI,

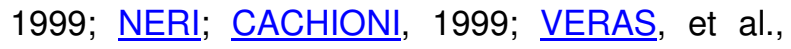

2004). Na área da Educação Física (EF) não é diferente, pois a criação de espaços e intervenções destinadas aos idosos cresce consideravelmente devido, especialmente, a um grande apelo de setores da Saúde Pública e dos meios de comunicação para o estímulo da prática de atividades físicas (AF) entre esse segmento populacional.

Além dos reconhecidos e bem documentados benefícios sobre $\mathrm{o}$ controle, tratamento $\mathrm{e}$ prevenção de doenças, de desordens, distúrbios e incapacidades funcionais, que são os mais difundidos e, em geral, metas primeiras das propostas de intervenção em AF/EF junto aos 
idosos, há iniciativas que se voltam para aspectos como integração social, saúde, qualidade de vida, socialização e fruição do lazer. Nenhuma dessas metas atendidas pelas práticas deixa de trazer consigo significações sobre a velhice, sobre o envelhecimento, sobre o que é viver bem e quais atitudes e comportamentos podem garantir uma velhice bem sucedida.

Por isso há que se reconhecer que a EF é também uma forma de intervenção sobre a vida das pessoas e aqui reside a sua natureza política. Isso traz à tona a necessidade de reflexões profundas acerca de quais paradigmas embasam os discursos e práticas de AF/EF junto aos idosos e em favor de quais interesses eles se voltam.

Essa reflexão torna-se especialmente importante quando percebemos que vivemos num momento, conforme já ressaltaram Debert (1999), Pires (2003), Minayo e Coimbra (2004), no qual muitos discursos e práticas na área da Saúde empenham-se em fazer da saúde e do estilo de vida saudável na velhice uma responsabilidade individual, desconsiderando aspectos socioculturais e políticos que interferem nas escolhas pessoais. Considera-se que o foco na responsabilidade do indivíduo sobre a sua saúde, via de regra, estrutura-se em torno dos interesses do Capital. Os mesmos autores mostram, ainda, como os manuais de saúde das revistas e dos programas de TV empenham-se em determinar, baseados no discurso científico, quais são os comportamentos adequados para que "a boa forma" e a aparência jovem sejam mantidas e os efeitos do envelhecimento sejam retardados. Assim, tanto a negação da velhice, quanto a visão estereotipada de velho e do envelhecimento são reforçadas.

Notamos que, infelizmente, esse discurso tende a ser incorporado pelo profissional de EF e, por conseqüência, norteia suas práticas, ainda que de maneira ingênua.

Com base nessas reflexões iniciais, propomos uma reflexão crítica sobre o papel da EF no contexto do envelhecimento como objetivo desse ensaio tendo como intuito a proposição de bases de um modelo pedagógico em EF para idosos que se debruce sobre as relações humanas de caráter emancipatório.

Por meio da articulação entre o referencial teórico que aproxima EF, Saúde Coletiva e Educação Libertadora na velhice, nossa intenção foi ampliar o debate sobre os papéis da EF junto aos idosos, apontado tanto os limites quanto uma provável tendência de esgotamento do modelo biomédico que ainda predomina nas intervenções em EF. Além disso, propomo-nos a pensar a EF para idosos fundamentada na ideia de autonomia e de emancipação, a partir do que tornar-se-á possível a formulação de propostas de intervenção.

\section{Educação Física e envelhecimento: ampliando o debate}

Um fato notório e amplamente reconhecido, tanto pela comunidade científica quanto pela sociedade em geral são os efeitos benéficos da prática de atividades físicas para a manutenção física e bem-estar psicossocial, principalmente sobre a população idosa (MATSUDO et al., 2001; MAZO et al., 2009; MIRANDA, 2001; OKUMA, 2002; STELLA et al., 2002; VELARDI, 2003).

Dadas as constatações científicas sobre os benefícios da prática regular de atividades físicas, as discussões em Saúde Pública reconhecem atualmente ser de suma importância para a adesão à atividade física, a implementação de programas educacionais que possam esclarecer a população idosa sobre os benefícios decorrentes desta prática, bem como sobre as recomendações mais apropriadas para que os idosos incorporem atividades físicas em sua vida cotidiana, tendo em vista que a adesão ainda é pequena ( $\underline{\text { CARDOSO }}$ et al., 2008; MATSUDO et al., 2002).

Deste modo, falar em Educação Física e Saúde, remete-nos a um processo amplo e complexo, que vai além da prática de atividades físicas. A educação, constantemente esquecida quando a prática de atividades físicas ocorre fora do ensino formal, deve ser parte indissociável de qualquer intervenção no âmbito da EF. Isso porque a atuação profissional nessa área, principalmente quando acontece em ambientes destinados à Educação em Saúde, configura-se numa relação de ensino na qual o educador e o educando revelam a característica eminentemente pedagógica da EF. No entanto, percebemos que, geralmente, não é dada a devida atenção aos aspectos educacionais nos programas de EF destinados ao público adulto. Como bem denotou Carvalho (2001), com frequência as preocupações dos educadores com seus educandos manifestam-se por meio da verificação de medidas classificatórias e 
avaliativas, como as medidas antropométricas, as faixas etárias, o gênero e a prevalência, incidência e risco de doenças crônicas não transmissíveis, além das medidas de aptidão física e funcional.

Ainda de acordo com Carvalho (2001), essa forma de conhecer as pessoas aproxima-as mais de um ser inanimado do que de um homem, de "carne e osso", que possui necessidades, desejos, percepções, aspirações... Isso nos conduz à pergunta já feita pela autora: onde está e quem é o sujeito dessas relações? Programas de "atividade física e saúde" são implementados para a população, mas os sujeitos a que se destinam essas ações parecem detalhes.

A impressão de que há a prioridade da conquista de um padrão de saúde ou desempenho em detrimento do sujeito reflete-se na produção científica e na atuação com a população idosa, especialmente quando percebemos que ainda são poucas as publicações e os profissionais da área da EF que lidam com essa fase da vida para além do declínio biológico que ocorre com a idade. Essa concepção do ser idoso e de saúde decorre do modelo científico cartesiano que ainda impera na área da Saúde (FAGUNDES; BURNHAM, 2005) e na EF (NOVAES, 2009). Muitas vezes essa concepção baliza as práticas junto aos idosos que, por consequência, tendem a ser estereotipadas e preconceituosas, como já indicou o estudo de Teixeira e Okuma (2004).

Aceitar um determinado conceito ou ideia de saúde e (incluímos aqui também) de velhice implica escolher certas intervenções efetivas sobre o corpo e a vida dos sujeitos. Por isso, como educadores, consideramos essencial a reflexão sobre quais conceitos e ideias de saúde, educação e velhice fundamentam nossas ações e por que frequentemente os sujeitos encontramse, (na maioria das vezes), ocultos nos discursos e práticas em educação física e saúde, conforme já ressaltou Carvalho (2001).

Para nós, compreender essas questões significa o reconhecimento da natureza política da ação educativa e o primeiro passo para materialização de uma práxis verdadeiramente comprometida com o ser idoso. Nesta questão, não podemos deixar de recorrer às reflexões de Paulo Freire, que nos ajuda a compreender a dimensão das perguntas colocadas anteriormente:
"Não posso ser professor se não percebo cada vez melhor que, por não poder ser neutra, minha prática exige de mim uma definição. Uma tomada de posição. Decisão. Ruptura. Exige de $\mathrm{mim}$ que escolha entre isto e aquilo. Não posso ser professor a favor de quem quer seja e a favor de não importa o quê" (FREIRE, 2002:102).

Assim, conscientes de que toda ação educativa é intencional, presumimos que há um modelo de homem e de sociedade que se quer efetivar ou legitimar. Acreditamos que o primeiro passo dessa reflexão é de caráter eminentemente filosófico, ou seja, o primeiro passo é indagar-se sobre o que é saúde e quais os fins a que se destina a educação.

Acreditamos, pautados na perspectiva proposta por Freire (2002), ser essencial a uma prática educativa o compromisso ético e incondicional com o "ser mais" e, por extensão, com o desenvolvimento da autonomia das pessoas idosas, aspecto tão valorizado nos discursos atuais da Promoção da Saúde a partir do Informe Lalonde e, posteriormente, da carta de Otawa (BUSS, 2003; OPAS, 1986). A autonomia dos sujeitos, como bem ressalta 0 ideário da Promoção da Saúde, é dependente da capacitação dos sujeitos e das comunidades, o que nos traz uma concepção bastante ampliada do que significa "promover saúde". Dessa forma, há que se refletir sobre o que se entende pelo conceito de autonomia, que na área de EF, é constantemente associado à independência física e a níveis satisfatórios de aptidão física e funcional (FARINATTI, 2002; FARINATTI e FERREIRA, 2006). Recorrendo aos referenciais da Filosofia, de acordo com Aranha e Martins (1993), a autonomia é entendida como uma capacidade eminentemente humana de fazer escolhas e responsabilizar-se por elas, a qual pode garantir às pessoas, mesmo na presença de doenças e limitações físicas, a possibilidade de manter o poder e o controle sobre suas vidas.

Em Freire e Shor (2003), vemos que o incremento da autonomia assim como o empowerment individual deve necessariamente desembocar num ato solidário, num engajamento dos sujeitos na luta pela libertação coletiva de toda forma de opressão e dominação, o que denota seu caráter político.

No que se refere aos idosos, diversos estudos vem chamando a atenção para as relações entre saúde e autonomia na velhice. Reconhecem que a imagem negativa do envelhecimento associada 
às perdas fisiológicas, psicológicas e sociais, que é predominante na sociedade brasileira contemporânea, pode provocar a diminuição ou o enfraquecimento da autonomia $e$ isso pode diminuir a saúde e a qualidade de vida percebida (LIMA, 2000; PALMA; CACHIONI, 2002; TEIXEIRA, 2002; VELARDI, 2003).

A autonomia é incrementada, principalmente, a partir de processos educacionais, levados a cabo também pela $E F$, seja no ensino formal ou nãoformal, como é o caso de sua inserção nas práticas de Educação em Saúde. Por isso, consideramos que encerrar os potenciais da EF na velhice, simplesmente no "fazer" atividade física e na enumeração dos benefícios físicos e funcionais decorrentes dessa prática seria desprezar o sentido latente da palavra "educação", expressa na denominação dessa área de conhecimento. Isso é particularmente relevante se considerarmos que estamos num momento em que o discurso gerontológico, como mostram Néri e Yassuda (2004), traz inúmeros argumentos em favor da educação na velhice, dentre os quais destacam-se a promoção de ganhos evolutivos, adquiridos a partir da troca de vivências e conhecimentos entre as pessoas, a aquisição de recursos internos para a manutenção da funcionalidade, para a adaptação e aceitação da velhice, além do aperfeiçoamento pessoal.

Assim, propomos que a EF, considerada como prática educativa, seja capaz de promover 0 desenvolvimento humano na direção do autocuidado que, em última análise, se refletirá em melhoras físicas e funcionais. No entanto, como prática educacional, a EF será ainda capaz de contribuir no desenvolvimento de uma consciência crítica que permita aos idosos refletirem sobre si mesmos, sobre suas realidades e sobre suas relações com o mundo, abrindo as possibilidades de discussões sobre 0 que significa viver essa etapa da vida.

Conforme afirmam Santos e Santos Sá (2000), ao envelhecer as pessoas se defrontam com novos desafios e novas exigências. Além de terem que lidar com as limitações de ordem física, estas são acrescidas daquelas que a sociedade estabelece como preconceitos e estereótipos que podem contribuem para o processo de exclusão social. Dessa forma, as autoras apontam que 0 grande desafio é construir permanentemente 0 próprio caminho, superando as dificuldades e integrando os limites e possibilidades de conquistar mais qualidade no seu viver. Como lidar, por exemplo, com uma sociedade excludente que valoriza o corpo belo e produtivo e, ao mesmo tempo, com a própria velhice que se evidencia no corpo?

Isso significa que o senso de pertencimento deva passar pela idéia de saúde e que, portanto, deverá fazer parte dos conteúdos e práticas pedagógicas da EF com os idosos. Parece ficar claro que atribuir prioritariamente à boa condição física a possibilidade de estar "incluído" e com "saúde" é simplificar um processo que vai além da superação dos entraves físicos que podem ocorrer com a idade.

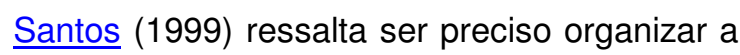
reconversão dos processos de socialização e de inculcação cultural para que a inclusão social ocorra de fato. Neste sentido, consideramos que a re-construção do modo de olhar a velhice tanto no âmbito individual quanto social, se dará, principalmente, a partir das possibilidades de participação em processos educacionais ao longo de toda a vida, inclusive na velhice. Tanto melhor será quanto mais esses processos educacionais desenrolarem-se em favor do desenvolvimento e da realização do ser humano ao invés de serem instrumentos a serviço do sucesso e da produtividade do sistema econômico.

Nesta direção, Both (2002: 1113) enfatiza que:

“... a educação, em face da longevidade, não pode mais permanecer com o mesmo projeto daquela que se baliza pelo sucesso produtivo e pela manipulação da natureza e das pessoas, cujo fim, não são elas próprias, mas sim, os interesses do sistema."

Para o mesmo autor, os ditames da ciência moderna e da tecnologia, que estão calcados na lógica da razão instrumental, não podem ser os parâmetros para uma educação comprometida com a vida e com a emancipação do ser humano, principalmente na velhice.

No entanto, percebemos que muitos discursos e práticas destinadas aos idosos, em inúmeras áreas do conhecimento, ainda são justificados por argumentos utilitaristas ${ }^{1}$. Na EF, por exemplo, esses argumentos são identificados nos discursos epidemiológicos utilizados para estimular a prática

\footnotetext{
1 Utilitarismo: Segundo Durozoi e Roussel (1996), é uma doutrina que coloca a utilidade como critério ou princípio da atividade do ponto de vista moral. É a teoria racional que permite determinar as técnicas que garantem o máximo de felicidade individual, reduzindo-se a um cálculo egoísta.
} 
de atividades físicas junto à população em geral a partir da explanação das consequências da inatividade física sobre os fatores de risco associados ao sedentarismo. Muitas vezes, uma parte dessa argumentação considera as relações entre os fatores de risco, o adoecimento e os gastos em Saúde Pública com doenças crônicas, ou seja, apontam o ônus decorrente da sobrecarga sobre as economias dos países industrializados como conseqüência de um número cada vez mais elevado de pessoas sedentárias e idosas.

Consideramos a importância da argumentação traçada pela epidemiologia, porém, quando ocorre nos termos supramencionados, a perspectiva epidemiológica tende a simplificar a complexidade inerente ao processo saúde-doença, principalmente se o uso das médias e desviospadrão, justifica propostas preventivas utilizandose da "teoria do risco" de forma acrítica (MINAYO; COIMBRA, 2004). Para Bagrichevsky e Estevão (2004), é aceitável que haja benefícios orgânicos decorrentes da prática de exercícios físicos, no entanto, é importante compreender que, adicionalmente:

\section{"... esta argumentação torna-se discutível, na medida que pretende sustentar uma política conservadora, uma dimensão moral que responsabiliza cada pessoa por seu próprio adoecimento e desconsidera a dinâmica sistêmica e multifacetária que influencia os estados de enfermidade humana"(BAGRICHEVSKY; ESTEVÃO, 2004: 04).}

Além de induzir à culpabilização da vítima ${ }^{2}$, nestes discursos não ter doenças parece encerrar em si o significado do que é viver. Nessa perspectiva algumas intervenções voltam-se mais para as doenças do que para a autorealização e para o potencial de desenvolvimento do sujeito que vive e está vivo, mesmo na presença de alguma doença ou limitação física. As motivações, as necessidades individuais e a autonomia dos idosos acabam sendo negligenciadas. Para Minayo e Coimbra (2004), no que concerne à saúde, um grande mercado consumidor que gira em torno da Geriatria refina

\footnotetext{
${ }^{2}$ Culpabilização da vítima: Na área da Promoção da Saúde, a expressão é utilizada para fazer uma crítica ao modelo biomédico que, a partir do reducionismo nos estudos do processo saúde-doença, atribui única e exclusivamente ao sujeito a responsabilidade pela suas condições de saúde, desconsiderando que, muitas vezes, ele é submetido a relações sociais desiguais impostas pelo seu meio capaz de torná-lo mais vulnerável e sem poder de reação, conforme explica Farinatti (2002) e Palma et al. (2003).
}

seus instrumentos e as medidas que rotulam o cotidiano e a existência dos idosos, desconsiderando a complexidade dos sujeitos e favorecendo a criação de uma estética para a vida que é referenciada em proibições e regras gerais de comportamento.

Em conseqüência dessa visão, as relações de ensino que geralmente se estabelecem e que se estendem também para a EF dão-se, muitas vezes, dentro de um contexto autoritário, seguindo um modelo de comunicação "unilinear" e unidirecional, em que o profissional, como reprodutor das verdades científicas, dita proibições e regras gerais de comportamento legitimando os valores dominantes de orientação individualista. Nesse processo, o profissional tende a tratar os indivíduos como receptáculos de informações (BAGRICHEVSKY; ESTEVÃO, 2004; VIEIRA et al., 1998).

Nesse sentido, retomamos os questionamentos propostos por Minayo e Coimbra (2004:13): "será que não existe a possibilidade de introduzir, na receita do que é saudável, o ingrediente prazer de viver como mote central dessa última e decisiva etapa da existência?".

Deslocar o foco para o sujeito, tratando-o de fato como sujeito e não como objeto, não é tarefa fácil. Exige um esforço considerável por parte dos envolvidos com a tarefa educativa. Para tanto, é necessário revermos as crenças e valores que justificam a submissão dos idosos às verdades unilaterais. Para isso é necessário que se compreenda a origem dessas práticas e por que os sujeitos estão frequentemente ocultos. Faz-se necessário compreender a estrutura conceitual que serve de suporte científico para a efetivação dessas práticas, bem como as visões de homem e de mundo que as norteiam. A partir disso poderse-á refletir sobre a importância da superação do modelo tradicional, pautado essencialmente nos posicionamentos ditados pelas verdades epidemiológicas a fim de que nossa prática esteja de fato comprometida com a existência humana.

\section{O paradigma biomédico, sua concepção de homem e a influência na Educação Física}

A influência do modelo cartesiano sobre o pensamento médico resultou no chamado modelo biomédico. Descartes, considerando que a materialidade do corpo deveria ser estudada pela ciência e a mente pela reflexão filosófica fundou 
um método que tem como base a dúvida. Para Descartes, só seria possível conhecer cientificamente aquilo que é dotado de uma realidade objetiva, pelo uso de um método capaz de colocar em suspenso tudo o que chega à consciência através dos sentidos provenientes da experiência no mundo. De acordo com a primeira orientação dada em seu "Discurso sobre o Método", o objeto do conhecimento deveria ser debulhado em quantas partes fossem necessárias, começando da mais simples para a mais complexa e, finalmente, submetidas a enumerações exatas (ARANHA; MARTINS, 1993).

A partir desse pensamento, parecia clara a necessidade de compreensão do corpo humano e do seu funcionamento de modo análogo às engrenagens de uma máquina ou ao funcionamento de um relógio submetido às determinações da natureza. Então o corpo passa a ser estudado em termos de suas peças observadas e analisadas separadamente. A compreensão mecanicista da vida, que tem seu expoente, posteriormente na física newtoniana, busca entender $e$ analisar o funcionamento orgânico a partir de relações causais possibilitadas por abstrações matemáticas, sendo o corpo e o seu movimento constantemente associados à máquina. Dessa forma, uma pessoa saudável passa a ser comparada a um relógio bem construído, funcionando em perfeitas condições mecânicas, já uma pessoa doente seria como um relógio cujas peças estariam desreguladas (ARANHA; MARTINS, 1993).

A base de todo o conhecimento e do status científico das Ciências da Natureza no século XVIII e XIX, como a Física, a Biologia e a Medicina, desenvolve-se a partir desse pensamento. $O$ corpo mensurável e fragmentado é desprovido de qualquer significado afetivo, social, histórico e cultural. Nesse sentido, Czeresnia (2003) afirma que o homem acaba tendo o seu corpo desconectado de todo o conjunto de relações que atribuem significado à sua vida. A partir dessa visão, o conceito de saúde passa a ser delimitado como a ausência de doenças, pois os mecanismos biológicos são vistos como a base da vida.

Dessa forma, o que não poderia ser apreendido através do método científico tendeu a ser visto como erro ou, ainda, como inexistente. Assim, o conceito de saúde desliga-se de toda a dimensão subjetiva, cultural e social, sendo olhado a partir do bom funcionamento orgânico.

O "normal e o patológico" passaram a ser circunscritos na perspectiva de esquemas calculáveis. Desse modo, a normalidade se define em termos de frequência estatística: é aquilo que se encontra em maior quantidade na média da população (CAPONI, 2003). Aqui, já percebemos que não há espaços para o diferente.

Assim, essa pretensa "neutralidade" científica tende a afastar das suas discussões tanto a complexidade inerente ao fenômeno Saúde/Doença quanto os determinantes (sociais, políticos, econômicos, dentre outros) que interagem e afetam a saúde dos sujeitos. Além disso, a doença é tratada como se tivesse vida própria, 0 que parece desconsiderar as experiências subjetivas de quem a vive, o que sente, quais são as suas necessidades, valores e desejos (CZERESNIA, 2003).

No século $X X$, o método cartesiano continuou influenciando as Ciências Biomédicas, sendo levado a cabo também pelo Paradigma Positivo nas Ciências Humanas, conforme demonstrou Santos (2003). Considerada "a filha emancipada" do método cartesiano, a ciência positiva traz consigo o otimismo dos ideais iluministas que conferia à razão o poder de libertar o homem dos desejos e impulsos e de reorganizar o mundo a partir das descobertas das relações previsíveis, constantes e necessárias entre os fenômenos. A partir de então, instaura-se a dúvida de todo e qualquer conhecimento que não esteja fundado pelos princípios epistemológicos e metodológicos baseados no rigor da observação, da verificação e da quantificação.

Em decorrência das conquistas provocadas por esse modelo de ciência, principalmente no que se refere ao avanço da tecnologia, essa lógica impõe a ruptura entre o saber do senso comum e o saber científico e cria "o mito do cientificismo", em que o único saber válido e com autoridade é o do cientista (CHAUí, 1995). Assim, a última palavra tende a ser sempre a do especialista, pois ele possui o discurso competente, cientificamente comprovado. Isso significa que, se há os que possuem o discurso competente há, por outro lado, aqueles que são os incompetentes e que devem se submeter ao discurso do poder. Isso redunda noutra dicotomia, conforme já apontou Aranha (1996): "a teoria manda porque possui as ideias e a prática 
obedece porque é ignorante", Essa afirmação deixa clara a perda da dialética teoria-prática.

$\mathrm{Na}$ área da Saúde, isso se reflete nas ações dos profissionais que "ditam" os comportamentos considerados saudáveis como padrão normativo, desconsiderando a necessidade de compreensões complexas sobre aquilo que, para além dos órgãos possa ter facilitado 0 desencadeamento dos processos "patológicos". O olhar sobre os quais estão as questões ambientais e os modos de vida impostos sobre as populações, sobre os quais o indivíduo tem pouco ou nenhum controle são, geralmente, esquecidos.

Como bem mencionou Caponi (2003), as práticas em saúde dirigidas através desse modelo têm como foco principal mudar o comportamento individual, ou seja, buscam a normatização de comportamentos, pois parece ser mais simples atribuir a culpa ao indivíduo do que procurar mudar condições perversas de sobrevivência.

Se pensarmos por essa lógica, perceberemos o quanto as doenças prevalentes na atualidade que atingem com mais frequência as populações que vivem nos grandes centros urbanos, as chamadas crônicas não transmissíveis, não podem ser pensadas e nem poderiam ser tratadas fora do ambiente e do contexto políticoeconômico no qual se desenvolvem: em estruturas políticas mais voltadas aos interesses de mercado do que aos interesses humanos, impondo aos indivíduos más condições de vida, relações de dominação, por exemplo, o que muitas vezes impede que os sujeitos sejam saudáveis, além de aumentar a vulnerabilidade às doenças, algo já discutido por Carvalho (2001); Palma (2000) e Palma (2003).

As condições que concederam status social à EF deram-se a partir do paradigma das ciências biomédicas, o qual, em meados do século XIX, começa a provar cientificamente os benefícios da prática de exercícios físicos no funcionamento orgânico. A EF, a partir dos métodos ginásticos, passa a ser fundamentada pelos princípios da racionalidade técnico-científica, da ordem e disciplina ditada pela burguesia em ascensão, que é a classe social que representa o poder, tanto no que se refere ao desenvolvimento científico quanto ao avanço do desenvolvimento industrial. Esse modelo de racionalidade científica também influencia fortemente a educação e, consequentemente, a formação e a atuação do profissional dessa área. Esse mesmo profissional justifica a sua prática enfatizando o caráter "medicinal" dos métodos ginásticos (RINALDI, 2005).

De acordo com Soares (2005) os métodos ginásticos que começam a ser introduzidos nas escolas neste período, tinham como objetivo contribuir para formar cidadãos disciplinados e saudáveis, para que pudessem aguentar as longas jornadas de trabalho dentro das fábricas, tornando as atividades corporais mais uma forma de manter o controle sobre a classe dominada.

Fora do âmbito escolar, a massificação da prática de atividade física ocorreu, principalmente, a partir da Segunda Guerra Mundial, por iniciativa dos EUA. Nesse período, a tendência pedagógica que começa ser difundida em diversos países, inclusive no Brasil, é o Tecnicismo. Baseada no modelo empresarial da objetividade e da eficiência, sua principal função é adequar a educação e o comportamento às exigências da sociedade industrial e tecnológica, sendo nítida a preocupação com a apropriação do saber científico, cabendo ao professor a transmissão e a execução daquilo que foi projetado pelos "donos do saber", ou seja, técnicos e burocratas do ensino (ARANHA, 1996). De acordo com a autora, essa vertente apresenta uma forte influência do positivismo e da psicologia americana behaviorista. Sendo herdeira do cientificismo, a tendência tecnicista busca, no behaviorismo, os procedimentos experimentais necessários ao condicionamento e ao controle do comportamento. Daí a preocupação com aspectos observáveis e mensuráveis.

É interessante notar como esse modelo foi apropriado pela área da educação em saúde. Basta percebermos as campanhas que, até hoje, tentam estimular, por exemplo, o comportamento fisicamente ativo. Ser sedentário ou obeso parece que virou problema moral, de conduta. É considerado um comportamento nocivo e que precisa ser normatizado.

Utiliza-se, dessa forma, uma "epidemia de números" sobre as doenças causadas pelos males do sedentarismo e que, conforme Fraga (2005), procura colocar a população em movimento através de uma "pedagogia do terror". Essa "epidemia de números" também se reflete na forma de avaliar as intervenções em atividades físicas. Os "princípios da eficiência" estão presentes ainda nos testes de aptidão física que 
procuram mostrar, em números, se o sujeito está ou não mais apto do ponto de vista físico ${ }^{3}$.

Dificilmente, cabem, nesses discursos, as perguntas "mais apto para que, ou para quem?". Não se discute, por exemplo, o lugar da liberdade humana, do direito de escolha, ou ainda, se esse sujeito tem entre o que escolher, considerando que a falta de oportunidade para a construção de sua autonomia, que esbarra na falta de cidadania, permite que se fique mais "vulnerável" a aderir a determinados comportamentos que podem influenciar negativamente na saúde individual e coletiva (PALMA, 2001; PALMA et al., 2003).

No campo da EF, observamos ainda com bastante freqüência, embora venha sendo paulatinamente superada, ações norteadas por essa visão. $O$ paradigma biomédico ainda embasa muitas intervenções nessa área, com a ênfase dada no "fazer atividade física". Entendemos que esse posicionamento reafirma uma visão dicotômica de homem, pois o enxerga somente em termos de seu "corpo biológico" e separado das relações concretas que estabelece com o seu mundo social. Isso poderá reforçar os preconceitos e a falta de respeito às diversidades em relação a quem não se enquadra em um padrão físico determinado como "bom ou normal" pela ciência, contra aqueles que vivem em situação de pobreza e vulnerabilidade e, portanto, não podem se engajar em atividades físicas ou ainda contra aqueles que simplesmente optam por não praticá-la.

Ao contrário, propomos uma prática pedagógica que, por meio da reflexão sobre a ação, permita a criação de conhecimentos sobre atividade física e o envelhecimento, julgados necessários para favorecer as escolhas livres e conscientes e a incorporação, modificação ou manutenção consciente e crítica de atitudes. Por meio das aulas práticas, os idosos podem ser estimulados tanto à reflexão sobre sua realidade quanto à compreensão da atuação do processo de envelhecimento sobre os diversos sistemas orgânicos. Surge daí a necessidade da compreensão do papel da atividade física no estímulo a esses sistemas, promovendo adaptações positivas e protetoras. Além disso, essas vivências corporais poderiam servir

\footnotetext{
3 Cabe ressaltar aqui que não se trata de questionar a importância e a necessidade da realização de testes de aptidão física, pois ele faz parte do diagnóstico para a implementação das ações nesta área. O que critico, neste ponto, é o fato de muitas práticas junto aos idosos se basearem simplesmente nesses parâmetros para chegar a conclusões sobre o sucesso de suas intervenções e da melhora da saúde dos indivíduos.
}

também como fio condutor das discussões sobre o processo de envelhecimento, estimulando reflexões críticas sobre si mesmo e a própria velhice, para que fosse possível a compreensão das razões que levam o estabelecimento e incorporação dos estereótipos negativos impostos pela sociedade de consumo, o que poderá contribuir para aceitação e mudança de atitudes ante a própria velhice (GEREZ et al., 2007).

\section{Considerações Finais}

Em função do aumento da população idosa, percebe-se atualmente um crescimento significativo no incentivo à prática de $\mathrm{AF} e$ a implementação de programas voltados para o atendimento das necessidades dos idosos tendo em vista os benefícios biopsicossociais que a prática pode proporcionar.

Considerando a importância do profissional de EF na organização e implementação das práticas de AF para idosos, é importante que a consideremos como uma forma de intervenção sobre a vida das pessoas. Como conseqüência, essa visão trará à tona a necessidade de profundas reflexões acerca de quais ideias e ideologias embasam os discursos e práticas da EF junto aos idosos. É preciso que tenhamos consciência de quais valores estamos perpetuando, principalmente num momento em que os meios de comunicação de massa, respaldados pelo discurso científico hegemônico, empenham-se em transformar a velhice e a saúde numa responsabilidade individual.

Diante disso, para nós parece clara e urgente a necessidade de reflexões sobre a prática pedagógica em EF para idosos para que, cada vez mais, sejam ampliados os espaços de construção de outros significados e práticas que acolham a diversidade e a complexidade desta fase da vida. Neste sentido, nos posicionamos em favor de uma prática pedagógica consciente e engajada em relações humanas e libertárias, que se comprometam com a superação da observação simplista dos fenômenos e considerem o contexto no qual se dão suas ações para, principalmente, promover aprendizagens sobre a EF e Saúde compromissadas com as escolhas e emancipação dos idosos, mesmo que essa escolha seja, eventualmente, não praticar atividade física.

Considerando o contexto exposto, as estratégias de Educação em Saúde no envelhecimento, dentre as quais se encontra a 
EF, podem proporcionar mudanças na visão negativa do envelhecimento pela diminuição da alienação, como já mencionou Teixeira (2002). Isto se daria através da reflexão sobre a ação vivenciada diretamente na prática de atividades físicas, ou seja, a partir da reflexão sobre a vivência do movimento, poder-se-ia incrementar os saberes sobre a atividade física bem como sobre o processo de envelhecimento, além de estimular o seu engajamento na luta pela transformação da sociedade opressora.

Acreditamos no potencial que a EF tem em auxiliar os idosos na construção de um posicionamento crítico diante da prática, além de possibilitar a abertura do campo de conhecimentos e reflexões sobre os determinantes da saúde, elevando a consciência política e as possibilidades de escolhas do indivíduo, deixando-o livre para decidir sobre seus comportamentos, concretizando, deste modo, o que Freire (2002) intitulou como uma "pedagogia da autonomia".

\section{Referências}

ARANHA, M.L.A. Filosofia da Educação. $2^{2}$ ed., São Paulo: Editora Moderna, 1996.

ARANHA, M. L. A; MARTINS, M.H.P.

Filosofando: Introdução à Filosofia. $2^{\mathrm{a}}$ ed., São Paulo: Editora Moderna, 1993.

ASSIS, M; HARTZ, Z. M. A; VALLA, V.V.

Programas de promoção da saúde do idoso: uma revisão da literatura científica no período de 1990 a 2002. Ciência e Saúde Coletiva, v.9, n.3, Rio de Janeiro, jul/set., 2004. Disponível em www.scielo.br. Acesso em 18/11/2009.

BAGRICHEVSKY, M; ESTEVÃO, A. Os sentidos da saúde e a Educação Física: Apontamentos preliminares. Revista Arquivos em Movimento, v.1, no1, Nov./2004.

BOTH, A. Longevidade e Educação:

Fundamentos teóricos e práticos. In.: FREITAS, E. V. et al. (orgs). Tratado de Geriatria e Gerontologia. Rio de Janeiro: Guanabara Koogan, p. 1111-1118, 2002.

BUSS, P. M. Uma introdução ao conceito de Promoção da Saúde - In.: CZERESNIA, D; FREITAS, C. M. (orgs). Promoção da Saúde: conceitos, reflexões e tendências. Rio de Janeiro: Fiocruz, p. 15-38, 2003.

CACHIONI, M; NERI, A.L. Educação e velhice bem-sucedida no contexto das Universidades da Terceira Idade. In.: NERI, A.L; YASSUDA, M.S.;
Cachioni, M. (Orgs.). Velhice bem sucedida: Aspectos afetivos e cognitivos. Campinas: Papirus, pag. 46-69, 2004.

CAPONI, S. A saúde como abertura ao risco - In.: CZERESNIA, D; FREITAS, C. M. (orgs).

Promoção da Saúde: conceitos, reflexões e tendências. Rio de Janeiro: Fiocruz, p. 55-77, 2003.

CARDOSO, A.S; BORGES, L.J; MAZO, G.Z; BENEDETTI, T.B; KUHNEN, A.P. Fatores influentes na desistência de idosos em um programa de exercício físico. Revista Movimento, Porto Alegre, v. 14, n.01, pag. 225239, jan/abril, 2008.

CARVALHO, Y.M. Atividade Física e Saúde: onde está e quem é o sujeito das relações? Revista Brasileira de Ciências do Esporte, v.22, n.2, p. 9-21, jan/2001.

CHAUÍ, M. Convite à Filosofia. $5^{\underline{a}}$ ed., São Paulo, Editora Ática, 1995.

CZERESNIA, D. O conceito de saúde e a diferença entre prevenção e promoção - In.: CZERESNIA, D; FREITAS, C. M. (orgs). Promoção da Saúde: conceitos, reflexões e tendências. Rio de Janeiro: Fiocruz, p. 39-53, 2003.

DEBERT, G.G. A Reinvenção da Velhice: Socialização e Processos de Reprivatização do Envelhecimento. São Paulo: Edusp-Fapesp, 1999.

DEBERT, G. G; NERI, A. L. (Org.). Velhice e Sociedade. 1. ed. Campinas: Papirus Editora, 1999.

DUROZOI, G; ROUSSEL, A. Dicionário de Filosofia. $2^{\mathrm{a}}$ ed. Campinas, SP: Papirus, 1996.

FAGUNDES, N.C; BURNHAM, T.F. Discutindo a relação entre espaço e aprendizagem na formação de profissionais de saúde. Interface Comunicação, Saúde, Educacional, v.9, ํㅜ16, p. 105-14, set.2004/fev.2005. Disponível em www.interface.org.br. Acesso em 01/04/2008.

FARINATTI, P.T.V. Atividade Física, Envelhecimento, e Qualidade de Vida. In: V SEMINÁRIO INTERNACIONAL DE ATIVIDADES FíSICAS PARA A TERCEIRA IDADE. São Paulo. Anais. p. 79-86, 2002.

FARINATTI, P.T.V.; FERREIRA, M.S. Saúde, promoção da saúde e educação física: conceitos, princípios e aplicações. Rio de Janeiro: EdUERJ, 2006. 
FRAGA, A. B. Prática física e cultura juvenil contemporânea. Revista do SESC/SP, São Paulo, p. 37-39, abril, 2005.

FREIRE, P. Pedagogia da Autonomia: Saberes necessários à prática educativa. $28^{\underline{a}}$ ed., São Paulo: Editora Paz e Terra, 2002.

FREIRE, P; SHOR, I. Medo e Ousadia: 0 Cotidiano do Professor. 10 ${ }^{\mathrm{a}}$ ed. Rio de Janeiro: Editora Paz e Terra, 2003.

FREITAS, E.V. Demografia e epidemiologia do envelhecimento. In.: NERI, A.L; YASSUDA, M.S. (orgs.): CACHIONI, M. (colab.). Velhice BemSucedida: aspectos afetivos e cognitivos, Campinas, SP: Editora Papirus, 2004.

GEREZ, A.G; MIRANDA, M.L.J; CAMARA, F.M; VELARDI, M. A prática pedagógica e a organização didática dos conteúdos de Educação Física para idosos no Projeto Sênior para a Vida Ativa: uma experiência rumo à autonomia. Revista Brasileira Ciências do Esporte, Campinas, v. 28, n. 2, p. 221-236, jan. 2007.

\section{LIMA, M.P. Gerontologia Educacional: Uma} pedagogia específica para o idoso: Uma nova concepção de velhice. $1^{\mathrm{a}}$ ed. São Paulo: Editora LTr., 2000.

MAZO, G.Z; CARDOSO, A.S; DIAS, R.G; BALBÉ, G.P; VIRTUOSO, J.F. Do diagnóstico à ação: Grupo de Estudos da Terceira Idade: Alternativa para a promoção do envelhecimento ativo.

Revista Brasileira de Atividade Física \& Saúde - Vol. 14, № 1, 2009.

MINAYO, M.C.S; COIMBRA JR, C.E.A. Entre a liberdade e a dependência: reflexões sobre o fenômeno social do envelhecimento. In: MINAYO, M.C.S; COIMBRA JR, C.E.A. (orgs.)

Antropologia, Saúde e Envelhecimento, 2a ed., Rio de Janeiro: Editora Fiocruz, 2004.

MATSUDO, S.M; MATSUDO, V.K.R; BARROS NETO, T.L. Atividade física e envelhecimento: aspectos epidemiológicos. Revista Brasileira de Medicina do Esporte, vol.7, № 1 - Jan/Fev, 2001.

MATSUDO, S.M.; MATSUDO, V.K; ARAÚJO, T; ANDRADE, D; ANDRADE, E; OLIVEIRA, L; BRAGGION, G. Nível de atividade física da população do Estado de São Paulo: Análise de acordo com o gênero, idade, nível socioeconômico, distribuição geográfica e de conhecimento. Revista Brasileira de Ciência e Movimento, v.10, n.4, p. 41-50, outubro 2002.

MIRANDA, M.L.J. Efeitos da Atividade Física com música sobre os estados subjetivos de idosos. Tese (Doutorado). Instituto de Psicologia da
Universidade de São Paulo-SP. São Paulo - SP, 2001.

NERI, A.L; CACHIONI, M. Velhice bem-sucedida e educação. In.: NERI, A.L; DEBERT, G.G (orgs.).Velhice e Sociedade. Campinas: Papirus, p. 113-140, 1999.

NERI, A.L; YASSUDA, M.S. (orgs.) Velhice bemsucedida: Aspectos afetivos e cognitivos. Campinas, SP: Papirus, p. 13-27, 2004.

NOVAES, C.R.B. Ciência e o conceito de corpo e saúde na Educação Física. Revista Motriz, Rio Claro, v.15, n.2, p.383-395, abr./jun. 2009. Disponível em http://cecemca.rc.unesp.br/ojs/index.php/motriz/ar ticle/view/1955/2394. acesso em 31/08/2009.

OKUMA, S.S. Cuidados com o corpo: Um modelo pedagógico de Educação Física para idosos - In.: FREITAS, E.V. et al. (orgs). Tratado de Geriatria e Gerontologia. Rio de Janeiro: Guanabara Koogan, p.1092-1100, 2002.

ORGANIZAÇÃO PANAMERICANA DE SAÚDE (OPAS). Carta de Ottawa. In.: Conferência Internacional Sobre Promoção da Saúde, 1., nov. 1986. Ottawa. Disponível em: http://www.opas.org.br/coletiva/uploadarq/ottawa.p df. Acesso em 13/11/2009.

PALMA, A. Atividade física, processo saúdedoença e condições socioeconômicas: uma revisão de literatura. Revista Paulista de Educação Física. São Paulo 14 (1):97-106, jan./jun. 2000.

PALMA, A. Educação Física, Corpo e Saúde: Uma reflexão sobre outros modos de olhar. Revista Brasileira de Ciência do Esporte, Campinas, v.22, n.2, p.23-29, 2001.

PALMA, A.; SALOMÃO, L.C; NICOLODI, A.G; CALDAS, A. Reflexões acerca da adesão aos exercícios físicos: comportamento de risco ou vulnerabilidade? Revista Movimento, Porto Alegre, v.9, n.3, set/dez., p. 83-100, 2003.

PALMA, L.T.S; CACHIONI, M. Educação Permanente: perspectiva para o trabalho educacional com o adulto maduro e com o idoso. - In.: Freitas, E.V. et al. (orgs). Tratado de Geriatria e Gerontologia. Rio de Janeiro: Guanabara Koogan, 2002.

PIRES, A. A batalha contra o tempo: relações com o corpo tendo em vista o processo de envelhecimento em Claudia e Playboy (anos 80 e 90). In: GUSMÃO, N.M.M. (orgs.). Infância e velhice: pesquisas e idéias. Campinas: Ed. Alínea, p. 59-76, 2003. 
RINALDI, I.P.B. A ginástica como área de conhecimento na formação profissional em Educação Física: encaminhamentos para uma reestruturação curricular. Tese (Doutorado). Faculdade de Educação Física, Universidade Estadual de Campinas, Campinas, 2005.

SANTOS, B.S. Pela mão de Alice: o social e o político na pós-modernidade. $6^{\underline{a}}$ ed. São Paulo: Cortez, 1999.

SANTOS, B.S. Um Discurso Sobre as Ciências. São Paulo: Cortez, 2003.

SANTOS, A.T; SANTOS SÁ, M.A.A. De volta às aulas: ensino e aprendizagem na terceira idade. In.: NERI, A.L; FREIRE, S.A. (orgs.) E por falar em boa velhice, Campinas: Papirus, 2000.

SOARES, C.L. Imagens da educação no corpo: Estudo a partir da ginástica francesa no século XIX. $3^{\mathrm{a}}$ ed. Campinas, SP: Autores Associados, 2005.

STELLA, F; GOBBI, S; CORAZZA, D.I; COSTA, J.L.R. Depressão no ldoso: Diagnóstico, Tratamento e Benefícios da Atividade Física. Motriz, Rio Claro, Vol.8 n.3, p. 91-98. Ago/Dez, 2002. Disponível em:

http://www.rc.unesp.br/ib/efisica/motriz/08n3/Stela .pdf. Acesso em 31/08/2009.

TEIXEIRA, M. B. Empoderamento como estratégia de Promoção da Saúde no campo do envelhecimento. Dissertação de Mestrado. FIOCRUZ, 2002.

TEIXEIRA, D.C; OKUMA, S.S. Efeitos de um programa de intervenção para idosos sobre a intenção de estudantes de Educação Física de trabalhar com este grupo etário. Revista Brasileira de Educação Física e Esportes, São Paulo, v.18, n.2, p. 137-149, abr/jun, 2004.

VELARDI, M. Pesquisa e Ação em Educação Física para Idosos. Tese (Doutorado). Faculdade de Educação Física, Universidade de Campinas, Campinas, 2003.

VERAS, R.P; CALDAS, C.P. Promovendo saúde e a cidadania do idoso: o movimento das universidades da terceira idade. Ciência e Saúde Coletiva, v.9, n.2, Rio de Janeiro, abr/jun. 2004. Disponível em www.scielo.br. Acesso em 18/11/2009.

VIEIRA, F.L; ANTONISSEN, K; ASSALIM, V.M; SILVA, A.P; YOSHIDA, V.C; CYRINO, E.G; PEREIRA, M.L.T. Outras leituras da realidade: alfabetização de adultos pela educação em saúde. Revista Interface - Comunicação, Saúde e Educação, n.2, fev/1998. Disponível em www.interface.org.br. Acesso em 05/05/2005.
Endereço:

Alessandra Galve Gerez

Universidade do Grande ABC - Curso de Educação Física

Av. Industrial, 3330 - Campestre

Santo André SP Brasil 09080-511

Telefone: (11) 4991.9878/2918.7466

(11) 9132.8295

e-mail: alegerez@ig.com.br

Recebido em: 5 de setembro de 2009.

Aceito em: 30 de dezembro de 2009.

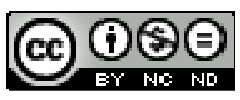

Motriz. Revista de Educação Física. UNESP, Rio Claro, SP, Brasil - elSSN: 1980-6574 - está licenciada sob Licença Creative Commons 